\title{
A ARTE DO TEATRO DE MAMULENGO NA ERA DIGITAL
}

\author{
THE ART OF MAMULENGO THEATER IN THE DIGITAL AGE
}

\section{Alexandre Figueirôa}

Doutor em Estudos Cinematográficos e Audiovisuais pela Universidade Paris 3 - Sorbonne Nouvelle (Paris/França).

Professor na Universidade Católica de Pernambuco (Recife/Brasil).

E-mail: alexandre.figueiroa@unicap.br

\section{Valeria Gomes}

Mestra em Indústrias Criativas pela Universidade Católica de Pernambuco (Recife/Brasil).

Professora do Centro Universitário Maurício de Nassau (Recife/Brasil).

E-mail:valeria.silva@sereducacional.com 


\section{Brazilian

\section{RESUMO}

O teatro de mamulengo é uma manifestação cultural tradicional nas cidades Glória do Goitá, Carpina, Lagoa de Itaenga, Vicência, Ferreiros, Nazaré da Mata, Tracunhaém e Itaquitinga, pertencentes à Zona da Mata Norte de Pernambucano. Utilizado como entretenimento, os bonecos utilizam do humor para fazer críticas sociais. Na era digital, cultura e tecnologia se entrelaçam. De um lado, a cultura preserva os saberes tradicionais, do outro, por meio de ferramentas digitais, abre-se um mundo de possibilidades para catalogação e divulgação do trabalho dos artistas mamulengueiros. $O$ presente artigo registra os processos de formação e construção do Mamulengo Arteiro, canal inscrito na plataforma YouTube, mo qual é feito um trabalho de reverberação da cultura popular do teatro de mamulengo. O projeto foi criado utilizando como ferramenta principal para sua elaboração o Design Thinking, e o produto audiovisual foi realizado majoritariamente em algumas cidades da Zona da Mata Norte de Pernambuco. Para fundamentação teórica do trabalho foram utilizados autores como Tim Brown (2017), John Howkins (2013) e Othon Jambeiro (2012). O Mamulengo Arteiro coloca os saberes tradicionais dentro do circuito dos setores criativos da atualidade.

Palavras-chave: Teatro de Mamulengo. Design Thinking. Produtos Criativos. Setores Criativos. Arte Digital.

\section{ABSTRACT}

The mamulengo theater is a traditional cultural, in the citys Glória do Goitá, Carpina, Lagoa de Itaenga, Vicência, Ferreiros, Nazaré da Mata, Tracunhaém, Itaquitinga, manifestation from the backlands of Pernambuco. Used as entertainment, the puppets use humor to make social criticism. In the digital era, culture and technology are intertwined. On one hand, culture preserves traditional knowledge. On the other, through digital tools, a world of possibilities for cataloging and publicizing the work of these mamulengo artists. The present article registers the formation and construction processes of Mamulengo Arteiro, a channel registered in the You Tube platform, where a reverberation work of the popular culture of the Mamulengo theater is done. The project was created using as main tool the Design Thinking and the audiovisual product was mostly made in some cities of the Northern Forest Zone of Pernambuco. For theoretical foundation of the work were used authors such as Tim Brown (2017), John Howkins (2013) and Othon Jambeiro (2012). The Mamulengo Arteiro places the traditional knowledge within the circuit of the creative sectors of today.

Keywords: Mamulengo Theater. Design Thinking. Creative Products. Creative Sectors. Art in the Digital Age. 


\section{Brazilian

\section{INTRODUÇão}

Este estudo se engaja na atual reflexão acerca da sobrevivência da cultura popular diante das mudanças tecnológicas incorporadas na globalização da informação, fato que revela desigualdades sociais de toda ordem. Por outro lado, em seu escopo, surge a possibilidade de que essa mesma globalização seja capaz de construir e potencializar "a associação, a participação democrática e a defesa de direitos sociopolíticos e culturais, ativando uma expressiva criatividade" (BARBERO, 2014, p.15). O pensamento de Barbero (2014) faz sentido na medida em que pode reduzir a negligência com as expressões culturais nas comunidades mais pobres quando não há incentivo para o aprendizado, cultivo e memória dessas tradições.

Ainda no meio dos processos mais brutais de recessão econômica, de desigualdade e exclusão, nossas sociedades vivem as transformações mundiais que associam um novo modo de produzir a um novo modo de comunicar [...]. Assim, se a revolução tecnológica das comunicações agrava o fosso das desigualdades entre setores sociais, entre culturas e países, ela também mobiliza a imaginação social das coletividades, potencializando suas capacidades de sobrevivência e de associação. [...] (BARBERO, 2014, p. 19).

Barbero (2014) afirma que há uma saída para que a cultura popular nessa fase da globalização, possa apropriar-se de ferramentas inovadoras, criativas e tecnológicas disponibilizadas pelo ciberespaço e dessa maneira gerar novos caminhos para os que lutam pela valorização da cultura popular. Dessa forma, é possível, dentro desse universo cibernético, ampliar a força raiz dessa cultura focando na trajetória histórica das manifestações populares, a exemplo do teatro de mamulengos que ao ser preservado nos seus locais de origem, ao longo do tempo, se consolida como patrimônio cultural do seu povo.

Ao promover os intercâmbios virtuais, as estruturas das "culturas cibernéticas" processam mudanças nas práticas comunicacionais e modificam a sensibilidade dos sujeitos no que se refere à compreensão do mundo e outras culturas. A atual cultura de rede, onde os indivíduos trocam conhecimento e divulgam novas maneiras de comportamento, dá oportunidade para que a diversidade cultural fique mais exposta por causa dos contatos de pessoas, ideias e significados.

Barbero (2014) fala que desde sempre comunicar significa narrar histórias, pois assim as culturas se conhecem entre si através das construções de suas próprias narrativas constituindo sua identidade coletiva. No campo da cultura, apesar do perigo de cooptação dos valores da cultura popular perante a globalização no que se refere a sua difusão, essa mesma difusão pode ganhar outra perspectiva caso 


\section{Brazilian \\ Creative Industries}

a falta de capital para investimento nas estruturas tradicionais de difusão sejam substituídas pelos dispositivos digitais, menos onerosos e mais acessiveis.

Pode-se então, sinalizar a possiblidade de se trazer um desenvolvimento social para essas culturas que, hoje, estão estagnadas, paradas no tempo e com o fazer manufatureiro reduzido a um puro processo criativo empírico. É preciso compreender, portanto que, na atualidade não há espaço para um olhar meramente nostálgico, deve-se olhar para o contexto da globalização e buscar nele reelaborações simbólicas visando a sustentação cultural. O desenvolvimento social atrelado ao uso das inovadoras tecnologias digitais, podem, assim, descortinar possibilidades de visibilidade, sustentabilidade e de preservação cultural, se utilizando dos novos instrumentos da indústria cultural e da economia criativa nas áreas da informação e das comunicações.

Tais instrumentos podem gerar nas comunidades uma consciência maior de conservação e renovação sobre o capital cultural produzido pelos indivíduos. É o caso, da cultura peculiar e singular do teatro de bonecos mamulengo encontrada em oito cidades da Zona da Mata Norte do Estado de Pernambuco: Glória do Goitá, Carpina, Lagoa de Itaenga, Vicência, Ferreiros, Nazaré da Mata, Tracunhaém e Itaquitinga. Essa rica expressão da arte popular vem declinando, paulatinamente, como potência cultural ao perder espaço para manifestações artísticas contemporâneas, por não angariar recursos suficientes para a sobrevivência dos seus brincantes, pelo desinteresse do poder público em incentivar e dinamizar sua prática e pelo desaparecimento dos seus mestres sem deixar herdeiros para manter viva a tradição. Apesar da existência de museus que exercem um papel de preservação dessa arte e algumas associações reunindo artesãos do teatro de mamulengo, notamos a falta de ações que revertam esse quadro, sobretudo, pela fraca divulgação dos espetáculos e a tímida inserção da manifestação nos circuitos de difusão cultural.

A ideia de buscar saídas para esta situação foi vislumbrada depois de diversas leituras sobre a economia criativa e percebermos a possibilidade de a disseminação dos espaços virtuais ser um agente para uma renovação e uma ressignificação cultural capaz de fazer o teatro de bonecos mamulengo recuperar parte do seu esplendor. Foi assim que, através de ações propositivas, elaboramos o projeto da construção do canal Mamulengo Arteiro, capaz de estabelecer um memorial digital para os que estão envolvidos com essa expressão artística.

Nossa perspectiva foi investir na comunicação, entendendo como ela pode assumir a tarefa de quebrar barreiras sociais, no sentido de descentralização da produção cultural, revitalização das identidades culturais e reconfiguração dos laços de contato da população local e visitantes com o acervo cultural dessas cidades em diversas esferas sociais, incrementadas pelo uso da internet. 


\section{Brazilian \\ Creative Industries}

\section{APORTE DAS INDÚSTRIAS CRIATIVAS}

O segmento das indústrias criativas é recente - anos 1990 - e engloba setores em que a criatividade se estabelece como ponto de partida para geração de saberes, mediante transformação dos valores sociais e culturais. Além do mais, se constitui, a partir do avanço da informação da sociedade pós-industrial, num potencial produtivo que se move rumo a economia, mas cujo valor se concentra, sobretudo, no capital intelectual e humano e na capacidade de troca de conhecimento, Bendassolli (2017). O caminho para a economia criativa se dá através da retórica da inovação, calçada na pessoalidade e originalidade da criação, Howkins (2013).

Como podemos ver, o teatro de bonecos mamulengo está dentro deste contexto. Tem uma estrutura (confecção dos bonecos, criação de histórias, manuseio dos bonecos etc.) dotada de valor criativo original e é uma produção autoral pela qual os seus artesãos e brincantes podem ser remunerados a partir dos seus múltiplos usos, portanto detentora de direitos autorais que precisam ser valorizados.

Desta forma, acenar para a criação de um produto criativo articulado com o campo da economia criativa que potencialize a transmissão de informação para uma comunicação de massa, nos parece uma proposta viável e útil para tal segmento da cultura popular pernambucana. A partir de um produto midiático, como o canal Mamulengo Arteiro, sinaliza-se a possivel geração de renda para os artistas, visto que uma maior visibilidade para eles deverá incentivar interesse pela aquisição de seus artefatos/produtos (bonecos), além de preservar seus espetáculos e saberes, enquanto seus detentores ainda estão vivos.

Ademais, se pode dizer que o teatro de bonecos mamulengo é matéria-prima para as indústrias culturais, pois são produtos passivveis de proteção sob o regime de propriedade intelectual, Jambeiro (2012). Seu insumo, alma criadora imaginativa libertária na feitura e criação de personagens, montagens improvisadas e instintivas das histórias, nos faz compreender a fantasia e captura da realidade do seu meio de produção.

Para novos espaços tecnológicos de informação, como é o caso do Mamulengo Arteiro, isso representa muito mais do que explorar um "ponto de vista" dos que exercem na arte de bonecos mamulengos. Significa também diminuir as desigualdades de acesso e capacidades/habilidades para geração e divulgação de novos conteúdos, visando a construção de uma memória digital e atualizada (JAMBEIRO, 2012, p.181 e 182).

Se por um lado o teatro de bonecos mamulengo está centrado em talentos individuais, do outro vemos a indústria cultural se estabelecer na esteira da lógica da produção de massa. Esse contexto para as indústrias criativas, todavia, pode ser repensado como um auxílio, caso deste projeto, de conceitos extraídos da economia política da comunicação, Jambeiro (2012). Ou seja, permitir que sujeitos criativos, 


\section{Brazilian

fora do universo do teatro de bonecos mamulengo, montem e complementem os talentos originais dos mestres mamulengueiros, utilizando-se de estratégias tecnológicas criativas no sentido de apoiar este setor específico que está marginalizado pela grande indústria cultural.

A informação é um ato de consumo e produto a ser comercializado a luz do entendimento do produtor, distribuidor e consumidor, pois esse contexto de circulação de conteúdo de mídia se presta à cultura participativa, Shirky (2012). Na atualidade, para gerar renda e principalmente fazer conservação de saber pela economia criativa, somos levados inexoravelmente à conexão com as mídias digitais e as redes on-line. O produto proposto - o canal Mamulengo Arteiro - se insere no fenômeno da mediação das redes sociais, no caso as plataformas YouTube, Instagram e Facebook, cujos poderes são inegáveis.

Com mais de 2,8 bilhões de usuários de internet no planeta em 2013 e mais de 6,4 bilhões de usuários de dispositivos de comunicação sem fio, redes horizontais de comunicação digital se tornaram a espinha dorsal de nossas vidas, materializando uma nova estrutura social que identifiquei anos atrás como sendo a sociedade em rede. (CASTELLS, 2001, p. 31).

Fica claro, ao nos referirmos à produção de informação, que as redes sociais, como ferramentas para conservação da cultura popular, são o foco principal desse projeto. Com elas pretendemos dar visibilidade a um produto cultural a partir da realidade vivida pelos próprios protagonistas - artesãos e artistas - de modo a divulgar seus saberes com a finalidade de proporcionar a eles a entrada numa economia criativa, por meio de plataformas digitais, esperando dessa forma gerar uma mudança no capital social da arte do teatro de bonecos mamulengo da Zona da Mata Norte pernambucana.

\section{UMA EXPERIÊNCIA DIGITAL NA CULTURA POPULAR}

Com a chegada do século XXI, não se pode negar que grandes avanços tecnológicos digitais foram absorvidos rapidamente por vários setores da economia industrial e sobretudo pelo setor da comunicação. A tecnologia digital se tornou um avassalador propulsor da informação, juntamente com a expansão do conceito da criatividade, oferecendo uma nova ordem para todos os setores produtivos no tocante à criação de riqueza e valores economicamente diferentes dos já existentes no mercado.

Desta forma, o ciberespaço professa uma nova forma de se relacionar em quase todos os ambientes sociais, Gibson (1984). Para Lévy (2010) ele é fruto de uma emergência exigida da própria evolução civilizatória, cuja função é o acesso à distância aos diversos recursos de um computador. Então, ele se torna um espaço de comunicação eletrônica aberto com interconexões mundiais que se expandem através 


\section{Brazilian \\ Creative Industries}

do ciberespaço - redes sociais. Assim, esse meio, tem habilidade de assentar e articular com sinergia e interfaces todos os dispositivos de criação no âmbito da informação e comunicação, segundo Lévy (2010).

De maneira que a universalização desse espaço catapulta a cibercultura, que se vê capaz de propagar interativamente, não só espaço físico, social e informal, mas qualquer realidade social. Pois é pelo seu poder de virtualização, "entidade da desterritorialização", como explica (LÉVY, 2010, p. 50), que mudanças inimagináveis ocorrem. Essa articulação intangivel e imaterial existente no ciberespaço, não se apresenta apenas na esfera comunicacional, mas propicia que as organizações e empresas transformem suas relações econômicas e financeiras pelo uso das ferramentas da cibercultura, principalmente, hoje, as redes sociais.

Recorrer a essa nova conjuntura propiciada pelos meio digitais nos soou, portanto, como um caminho natural a ser experimentado. $O$ trabalho, por nós desenvolvido, buscou então ter como foco a construção de um artefato digital audiovisual, articulado em redes sociais com a finalidade de salvaguardar e difundir, o teatro do mamulengo. O produto audiovisual, intitulado canal Mamulengo Arteiro, propõe buscar um novo protagonismo do teatro de mamulengo através de ferramentas digitais de produção e de difusão, bem como a construção de uma linguagem própria para reverberar o mamulengo tradicional, moldando conteúdos a fim de chegar em um produto diferenciado, ampliando o seu alcance, hoje concentrado e quase restrito à Zona da Mata do Estado de Pernambuco.

As ações buscaram provocar impacto, tornando visíveis os mestres mamulengueiros mais antigos, os que já faleceram e os ainda em atividade com a intenção, sobretudo, de sensibilizar os poderes públicos locais e estadual para assumirem responsabilidade social com estes protagonistas. Esse produto digital também tem o propósito de ser algo criado para outros atores sociais terem a oportunidade da experimentação e do contato com aspectos diferentes que compõem a cultura tradicional deste teatro.

A montagem do canal e de seus objetivos foram trabalhados usando o processo do Design Thinking, Brown (2017) por meio de uma abordagem racionalista, tendo em vista a construção das etapas de prototipagem. Com isso, realizamos uma observação amiúde do seu desenvolvimento e da sua adesão digital, sabendo o quanto as novas tecnologias mudam comportamentos e a forma de se relacionar com todas as áreas da sociedade.

Ao colocarmos nosso objeto de estudo e pesquisa no ambiente do design, associando a forma (pelos aspectos estéticos e simbólicos) e a funcionalidade (pelos aspectos técnicos e práticos), buscamos uma mudança de cenário a partir da construção desse produto midiático. Acreditamos que a expertise criativa, a análise e as estratégias delas decorrentes podem ser capazes de construir ressignificações e concretizar uma mudança de padrão tanto de produção como de um novo olhar para o teatro de mamulengo. 


\section{Brazilian \\ Creative Industries}

Além do mais, o intuito foi cristalizar esse produto como um vetor de inclusão, específico para o teatro de mamulengo tradicional e fazer dele um produto possivel de ser aplicado em novos projetos com outras manifestações populares que estejam em declínio social, pois as novas tecnologias propiciam muitas articulações. Para isso, fomos buscar amparo teórico da economia criativa proposto por Howkins (2013) que se articula com a criatividade como fator motriz para os setores criativos, dentre os quais se encontram o audiovisual.

Sabemos que a economia criativa articulada pelas políticas públicas produz estímulos ao conhecimento, valorização e estímulo para as atividades culturais e criativas contribuindo para o desenvolvimento econômico. Esse desenvolvimento quando se refere a dimensão cultural, sobretudo ao acesso da informação e comunicação, gera bens e serviços culturais, facilitando a geração de renda, emprego, exportação, valor agregado e arrecadação de impostos. Desta forma, cresce o impacto e influencia a formação e qualificação do capital humano, reforçando, ao mesmo tempo, elos identitários através do acesso à cultura.

Os gestores políticos e agentes de produção cultural, sabem que a cultura gera renda, emprego e inclusão, pois ela é importante para o crescimento dos setores criativos através de atividades que se estruturam junto ao turismo, vetor que por si só aceleram as economias locais, regionais e de um país. Dados fornecidos pelo site em 2012 da Federação das Indústrias do Rio de Janeiro (FIRJAN) com base nos estudos do IBGE, as atividades culturais e criativas geram, 2,64\% do PIB brasileiro e são responsáveis por mais de um milhão de empregos formais diretos, cujo setor tem 250 mil empresas e instituições atuantes. Entretanto, esta não é uma realidade para a Zona da Mata Norte pernambucana, pois não há suporte financeiro de origem pública ou privada aos que se encontram envolvidos com o teatro de bonecos.

O protótipo do canal Malulengo Arteiro, agente dessa pesquisa, no contexto da propriedade intelectual do mamulengo, visa assim também ajudar, por meio da promoção digital, a sobrevivência econômica dessa arte popular e de seus atores.

\section{DESENVOLVIMENTO DO PROJETO}

A ideia para o projeto do Mestrado de Industriais Criativas surgiu através da observação e orientação de um trabalho de Conclusão de Curso de Jornalismo - Fotodocumentário com o título Mestre Zé de Bibi - Do mamulengo ao Cavalo Marinho realizado por Daianne Luna, no ano de 2015, quando percebemos a pouca visibilidade para as duas manifestações populares em Pernambuco.

$O$ insight para a montagem do projeto ocorreu para atender uma das exigências do processo de seleção do mestrado e teve como premissa oferecer a oportunidade para um protagonismo do teatro 


\section{Brazilian \\ Creative Industries}

de mamulengo, principalmente na cidade de Glória do Goitá. Uma pequena pesquisa historiográfica sobre onde se localizavam os núcleos desses saberes e ofícios foi articulada e, além de Glória do Goitá, identificamos mais sete cidades na Zona da Mata Norte pernambucana que poderiam se beneficiar com o projeto. Pesquisando em documentos do Ministério da Educação encontramos ainda um Dossiê Interativo - Registro do teatro de bonecos popular do Nordeste: Mamulengo, Cassimiro do Coco, Babau e João Redondo como Patrimônio Cultural do Brasil - realizado em Brasília, publicado em 2014, que mostrava os processos de registro das Associações de Mamulengueiros e Mestres de Pernambuco. De pose desses registros dos dados dos mestres mamulengueiros percebemos a viabilidade do trabalho, pelo menos nas oito cidades onde essa cultura popular estava ativa e com capacidade de expansão.

A construção do projeto, na fase inicial do processo criativo do produto, se configurou em um levantamento realizado no YouTube de modo a observar como o teatro de mamulengo estava sendo veiculado nesta plataforma de vídeos: Dentre vários canais na plataforma, selecionamos uma amostragem para fazer a análise de conteúdo num total de seis canais: Teatro Gil e Cris, Rede Potiguar de Televisão Educativa e Cultural, Pindorama Arte Brasileira, Gavetas Malucas, Carroça de Mamulengos, TV Brasil Gov. 0 objetivo da análise era observar como a arte popular do teatro de mamulengo se apresentava e como o público o recebia. Constatamos então que a maioria desses canais se utilizam da linguagem e da estética da arte do mamulengo com objetivos educacionais e prestação de serviço em campanhas publicitárias governamentais e não articulam nenhuma referência histórica sobre a cultura do mamulengo. Ou seja, desde o primeiro momento percebemos a necessidade de um resgate histórico e de uma oportunidade para o teatro de mamulengo recuperar seu protagonismo entre os folguedos populares a partir da difusão nas redes sociais.

Já para o desenvolvimento do protótipo do canal Mamulengo Arteiro aplicou-se a metodologia do Design Thinking. Segundo Brown (2017), vivenciar o Design Thinking é sempre visitar estados mentais, no sentido de uma avaliação da viabilidade do processo criativo (BROWN, 2017, p.63). Para esse autor, o processo criativo estabelece quatro etapas para se ter boas ideias. A primeira etapa é a preparação tentativa de solução com esforço consciente. Nesta fase, o objetivo principal é entender a questão ou projeto e absorver as informações a respeito dele. É a etapa do estudo, informações e da pesquisa para definição de tema, possíveis caminhos, público-alvo e obstáculos que envolvem sua viabilidade.

Na etapa de preparação do nosso projeto, começamos a fazer uma revisão bibliográfica sobre o teatro de mamulengo, para a formação e adesão de sentido sobre o objeto da pesquisa. De imediato percebemos a escassez de títulos publicados. Começamos pelos títulos bibliográficos históricos Mamulengo, um povo em forma de bonecos, Santos (1979); Espetáculo Populares do Nordeste, Borba Filho, (1966); Fisionomia e espírito do mamulengo (O Teatro Popular do Nordeste), Borba Filho (1966); Mamulengo, 


\section{Brazilian

o teatro mais antigo do mundo, Jaziello (2003) e Teatro de Bonecos Popular do Nordeste Mamulengo, Babau, João Redondo e Cassimiro Coco como Patrimônio Cultural do Brasil, Brochado (2015).

A segunda etapa, a incubação, é o momento de se olhar para as informações coletadas nos estudos e na pesquisa no sentido de se obter associações relevantes entre elas, porém num processo mental fluido, deixando as ideias correrem inconscientemente. Seguindo esses passos, mediante as bibliografias colhidas e das informações sobre o objeto da pesquisa - mamulengueiros e mestres da Zona da Mata Norte do Estado - fizemos um brainstorming com produtores culturais ligados a cultura popular do mamulengo e visualizamos que seria importante formular um projeto em que fosse possivel agilizar, através das ferramentas digitais, essa cultura popular tanto para salvaguardar a memória dos que a fazem quanto para proporcionar um protagonismo digital desses artesãos e brincantes.

A iluminação é a terceira etapa do processo criativo. Como a terminologia sugere, é o insight. Momento da clareza da ideia do projeto que se estabelece e os pensamentos se tornam mais concretos, as ideias começam a tomar forma, mais claras e embasadas. Para nós, foi o momento de certeza de que já tínhamos uma ideia clara sobre os passos seguintes e poderíamos, assim, articular um canal no YouTube que fosse exclusivo para dar visibilidade aos mestres da Zona da Mata Norte, berço secular do teatro de mamulengo em Pernambuco. Isso nos levou a buscar um desenvolvimento consciente do projeto a partir de uma revisão bibliográfica na qual pudéssemos ancorar teoricamente esse percurso, sobretudo o funcionamento da internet e o papel das redes sociais que tem oferecido às pessoas ferramentas indispensáveis nos processos comunicacionais da contemporaneidade.

A quarta etapa, conforme Brown (2017) é a implementação ou prototipagem, fase de colocar e aplicar em prática a ideia e gerar um resultado. A prototipagem é uma fase no processo de construção e testes, avaliações do protótipo que pode exigir adequações e mudanças para o seu aprimoramento. 0 protótipo se apoia na criatividade que ajuda o designer a capturar e gerar ideias que facilitem a exploração e descoberta de informações relevantes sobre o usuário e suas práticas com relação ao protótipo que está sendo desenvolvido. No nosso caso, como o artefato audiovisual canal Mamulengo Arteiro é um protótipo digital, nessa etapa fizemos os roteiros das entrevistas e vídeos a serem realizados e, na medida em que eles foram sendo postados, avaliamos e testamos o seu desenvolvimento

\section{O PRODUTO}

Para chegarmos em um produto criativo, devemos entender que ele é fruto de um processo a partir de um conjunto de passos para organizar pensamentos e ideias a fim de colocar o que foi pensado em prática. Esse processo pode ser desenvolvido por um indivíduo ou por uma equipe, no sentido de 


\section{Brazilian

simplificar o esforço direcionado para as etapas (gerações de ideias e soluções) a serem desenvolvidas. Na construção do produto, não se deve perder de vista que há duas características importantes: ele tem que ser resultante de uma atividade criativa com significado próprio ou de uma ressignificação e ter um valor econômico reconhecivel.

Na estruturação do canal Mamulengo Arteiro buscamos embasar essa estrutura nos quatro princípios do planejamento estratégico propostos por Djalma Oliveira:
"a) princípio da contribuição pela hierarquia dos objetivos do planejamento;
b) princípio da precedência do planejamento - atribuir funções, direção, pessoal;
c) princípio das maiores influências e abrangência que agi na visão de modificação mediante necessidades no decorrer do processo;
d) princípio das maiores - eficiência, eficácia e efetividade." (OLIVEIRA, 2013, p. 7).

As etapas realizadas foram as seguintes:

Etapa 1) Escolha do nome do canal entre diversas opções: Viva o Mamulengo!; Mamulengo Jiboia; Mamulengo pernambucano; Mamulengo Arteiro; Canal Mão Mole. Para a escolha do nome foi observado o conceito que se enquadrasse com o perfil do conteúdo que seria produzido. A palavra "arteiro" é um adjetivo que significa tranquilo, levado, travessuras, esperteza, perspicácia, artimanha, sagacidade. Observando o universo do teatro de mamulengo esses adjetivos o representam.

Etapa 2) Definição da programação visual. Como precisávamos de um designer para criar a identidade visual do canal, escolhemos o designer Mano Lee que então produziu as artes para a capa perfil do canal e os ícones para serem utilizados nas aberturas das produções audiovisuais e das redes sociais (Instagram, Facebook). 


\section{Brazilian Creative Industries}

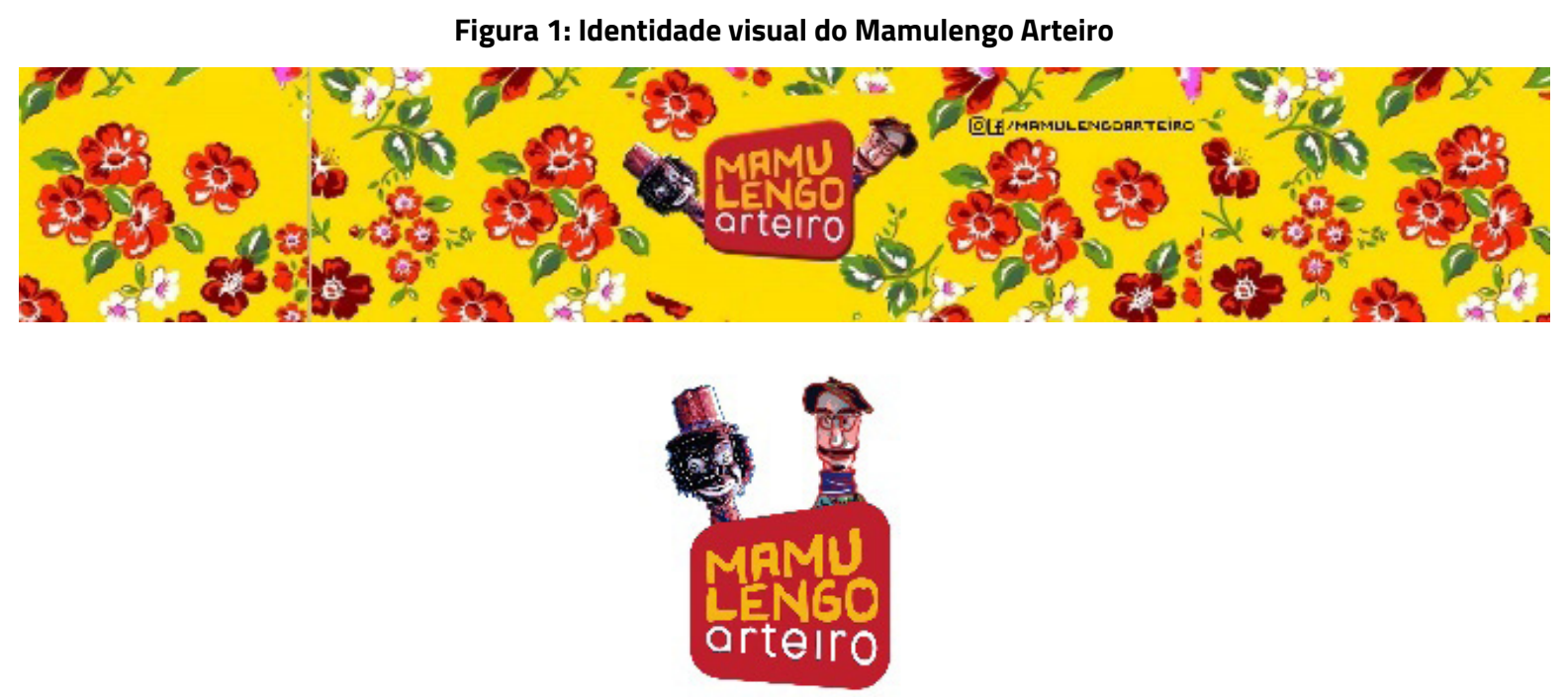

Fonte: A autora (2021)

Etapa 3) Escolha da equipe de audiovisual. Definimos a composição da equipe com três captadores de imagem e áudio (Valéria Gomes, Silvio Francs, Marina Araújo) e o equipamento: 4 câmeras fotográficas, 4 microfones - 1 tascam, 3 lapelas, 2 direcionais -, boom, 4 tripés, rebatedor, difusor e bloqueador, iluminação contínua - 4 lâmpadas com 4 softbox -, e 3 computadores para fazer as edições dos vídeos.

Etapa 4) Realização de vários encontros para a criação da comunicação do canal; definição das categorias (playlists) que o canal deveria ter e quais os tipos de linguagem que poderiam ser criados para os vídeos a serem produzidos.

Neste ponto, achamos relevante, destacar um dos alicerces desse projeto: o uso de recursos audiovisuais. Na atualidade, além dos registros em livros e trabalhos de pesquisa acadêmicos da cultura popular sobre o teatro de bonecos mamulengo, para uma manifestação popular tão rica em detalhes de produção e de espetáculo, se faz necessária a utilização de meios tecnológicos que Ihes proporcionem também uma experiência sensorial. As vozes que contam as histórias e que cantam, o ritmo e entonações para os enredos construídos de improviso, o colorido que envolve a barraca (espaço onde são apresentadas as peças), as roupas coloridas e exóticas dos diversos personagens e tantas peculiaridades são elementos que ganham outra dimensão com o uso da imagem em movimento.

Por isto é importante o uso da linguagem audiovisual como ferramenta para protagonizar e salvaguardar o teatro de bonecos mamulengo da Zona da Mata Norte do estado de Pernambuco. Os recursos tecnológicos hoje disponibilizados permitem criar produtos de comunicação que nos invadem com relatos extraídos da vida real pela natureza sonora e imagética dessas expressões, se constituindo 


\section{Brazilian \\ Creative Industries}

um artefato cultural que afeta imensamente o homem pós-moderno, Hall (2011). Como a produção audiovisual está diversificada e participa da indústria cultural, vemos que a celeridade de divulgação de seus conteúdos transcorre em todas as plataformas de difusão de conteúdos ancoradas nas novas tecnologias, a saber: YouTube, Instagram, Spotify, Facebook etc.

Reforçando o papel do audiovisual na cultura contemporânea e sua potência sensorial, gostaríamos de apontar um outro exemplo desse processo que são as obras literárias adaptadas para a televisão e para o cinema, bem como em vídeos na internet. O conteúdo presente na literatura é impulsionado para o audiovisual no sentido de preservar a totalidade de suas características estéticas, acrescentando, porém, novos elementos (movimento, música, cenários) que tornam mais dinâmica a experiência cultural. O mesmo acontece com peças teatrais e, dessa forma, o teatro de mamulengo pode tranquilamente ser inserido nesse circuito. Além do mais, ao abordar expressões da cultura regional, tais iniciativas ajudam as comunidades locais a reconhecerem seu valor identitário.

A produção audiovisual do canal Mamulengo Arteiro foi iniciada em 2019 e se estendeu até 2021 de acordo com as seguintes fases na produção de cada vídeo:

1. Contato com a intermediadora, Mestra Titinha (à época, diretora do Museu do Mamulengo de Glória do Goitá- PE);

2. Delimitação do mestre e da cidade da Zona da Mata Norte de Pernambuco;

3. Contato com o mestre para verificar disponibilidade de gravação;

4. Gravação da entrevista (com roteiro livre, não-linear, a partir da fala de cada mestre);

5. Edição de vídeo (utilizado os programas Adobe Premiere Pro, Adobe Photoshop, Adobe After Effects);

6. Criação de teasers promocionais da entrevista para o Instagram Mamulengo Arteiro;

7. Publicação da entrevista no canal Mamulengo Arteiro;

8. Publicação de teasers promocionais no Instagram Mamulengo Arteiro

9. Divulgação da entrevista no WhatsApp e Instagram.

O Mamulengo Arteiro conta com produções audiovisuais como: videoclipes, entrevistas, informativos de eventos que se articulam por produções de conteúdos na plataforma YouTube. Contém ainda cinco pastas nomeadas em conteúdo distintos e originais (Viva os Mestres do Mamulengo; Borogodó News; Senta que lá vem a história; lapôe!; Acervo Digital do Museu do Mamulengo de Olinda), além de usar o Spotify e o Instagram como ferramentas de visualização para o canal.

O canal Mamulengo Arteiro foi ao ar em 4 de junho de 2020 e possui 14 produções audiovisuais disponibilizadas no YouTube:

- Sabe de onde vem o nome MAMULENGO? 


\section{Brazilian \\ Creative Industries}

- Conheça os personagens do Mamulengo- Mestra Titinha

- Mestre Bel| Ep 01 - A tradição tem que continuar

- Mestre Zé de Vina| Ep 02 - Vida e história

- Mestre Bila|Ep 03 - Dificuldades e o nascimento de um museu

- Mestre Zé Lopes | Ep 04 - Memorial

- Mestre Zé de Vina | Ep 05 - Entrevista ao canal Coletivo Parêa

- Mestre Bibiu do Boneco| Ep 06 - Formação de identidade e Estilo

- Mestre Biu de Dóia | Ep 07- Música e brincadeira

- Mestre Vitalino Mamulengueiro | Ep 08-Arte eletrificada

- Mestre Saúba| Ep 09-Melancolia e vida

- O Mamulengo e a criatividade em contar histórias

- Canal Mamulengo Arteiro

- Borogodó News \#01

\section{CONSIDERAÇÕES FINAIS}

Ao encerrarmos a elaboração do projeto canal Mamulengo Arteiro, ficou claro para nós que, na contemporaneidade, abraçar as tecnologias digitais é um caminho viável para quem se propõe a construir relações entre um meio orgânico, como o do teatro de bonecos do mamulengo, e as redes digitais, pois elas oferecem a possibilidade de se potencializar as interações entre artistas e sociedade. Nesse sentido, a participação da Mestra Titinha - Edjane Lima - à época diretora do Museu do Mamulengo de Glória do Goitá no levantamento inicial do projeto foi fundamental. A partir dessa vivência, verificamos o fato de que, sem o exercício cotidiano do envolvimento dos cidadãos na designação de suas reais expectativas e demandas não haverá espaço para a cultura se consolidar. É importante que os indivíduos sejam autores dos processos que envolvam decisões individuais e coletivas relativas às questões culturais.

Observamos também que uma intervenção como esta pode recorrer a tecnologia para esta demanda, sem esquecer, porém, de se preservar o caráter tradicional da manifestação popular. Com a contextualização midiática proposta para o teatro de bonecos do mamulengo, ganhou-se uma nova roupagem na reverberação do produto cultural, oferecendo, ao mesmo tempo, recursos impulsionadores e atrativos ao público, sem, no entanto, o desvincular das raízes mamulengueiras: ludicidade, artesanato e contação de histórias. Para isto constatamos quanto o audiovisual se mostrou a ferramenta ideal para consolidar esse processo, pois o audiovisual preserva em sua totalidade todas as características estéticas 


\section{Brazilian \\ Creative Industries}

que o mamulengo tem, ele registra movimento, música, entonação, seu texto em forma oral, tudo isto apresentado por meio de espetáculos filmados ou por vídeos documentais.

Além disso, a partir das experiências realizadas, verificamos que o Mamulengo Arteirotem respondido às hipóteses levantadas quando iniciamos o projeto, pois ele está se configurando como um importante processo comunicacional de agregação de informação a partir de um canal e suas redes sociais. Tal premissa fica clara quando observamos que a maioria de seus seguidores são participantes desse segmento cultural e o veem como uma plataforma de comunicação, um espaço para obter informações e divulgar o que está sendo produzido em várias partes do Estado de Pernambuco na arte do mamulengo: eventos teatrais; lançamentos de livros; oficinas de bonecos; feiras de venda de bonecos. Visualizando o Mamulengo Arteiro pode-se ainda entrar em contato com mestres mamulengueiros para conhecer suas biografias e suas produções, por meio de entrevistas e documentários sobre a história da expressão produzidos para o canal.

O canal Mamulengo Arteiro no YouTube conta atualmente com 313 inscritos e os 16 vídeos disponibilizados somam 8.249 visualizações. Os vídeos mais vistos são os que trazem entrevistas com os principais mestres do teatro do mamulengo da Zona da Mata pernambucana. 0 episódio 06, com Mestre Bibiu do Boneco tem, até o momento, 1,3 mil visualizações; em seguida vem o episódio 03, com Mestre Bila, com mil; o episódio 02, com Mestre Zé de Vina, com 950; e o episódio onde os personagens do teatro do mamulengo são apresentados por Mestra Titinha, com 800. Esses resultados nos mostram o maior interesse dos espectadores pelas formas tradicionais da arte do mamulengo. Ao mesmo tempo, porém, verificamos, com a produção dos vídeos, duas alternativas de sustentabilidade para esta expressão que podem ser encampadas pelos artesãos e artesãs brincantes, um item importante na conjuntura atual: a comercialização de bonecos e adereços. A primeira foi observada junto aos bonequeiros vinculados à Associação de Mamulengueiros e Artesãos de Glória do Goitá (ARTESOL). Eles estabeleceram um processo de criação, seguindo o mesmo modelo de corte, cor e forma, ou seja, uma estética padrão de fácil e rápida reprodução. Esse processo, embora dificulte identificar o autor das peças por não possuírem uma identidade que enfatize os traços da mão do criador, facilita a comercialização do que eles produzem. Por outro lado, encontramos mestres, não vinculados a ARTESOL, que possuem processos de criação específicos, seus artefatos apresentam traços facilmente identificáveis com seu criador, que não se confundem com peças criadas por outros bonequeiros, mas que são valorizadas exatamente por sua originalidade.

Quando analisamos a audiência do Instagram do canal Mamulengo Arteiro (agosto/ 2021), o gráfico nos mostra uma variedade de acessos de localidades: Recife com 17,1\%; São Paulo 8,2\%; Glória do Goitá 3,1\%; Fortaleza 3.8\%; Brasília 3,8\%. Isso indica que há um interesse pela arte popular do teatro mamulengo. 


\section{Brazilian

Uma postagem de abril de 2021 divulgando o link para o canal do YouTube, do vídeo que conta a história dessa expressão, teve 476 reproduções. Outro gráfico fornecido pelo Instagram informa que entre os que acessaram o canal 63,3\% são do gênero masculino e 36,7\% do gênero feminino. As faixas etárias que mais acessaram o canal estão com idade entre 25-34 e 35-44 anos, com o percentual de 28,7\% e 22,2\%. Já a faixa etária de 45-54 anos representa 23,5\% dos acessos nas cidades onde a audiência do Instagram do canal Mamulengo Arteiro foi aferida.

Observando ainda o Instagram vemos diversos mestres e artesãos oferecendo informações de eventos e informações sobre o teatro de mamulengo. Entre nossos seguidores e curtidores temos, entre outros, os perfis: @ciamamulengogratidao; @bonequieromamnuel; @mamulengo_lengotengo; @ catarinacalungueira; @mamulengorasga; @teatroparambuco; @flordomamulengo30; @babaulego; @ coletivogoiabinha; @actb_teatro_de_bonecos; @bonequeiraspotiguares. É importante observar que o perfil do Mamulengo Arteiro ganhou mais seguidores do que perdeu, o que reforça a possibilidade de que estamos adquirindo audiência e cativando um público para essa manifestação popular. Nos dados fornecidos constatamos que, no período de 31 de julho a 29 de agosto/2021, alcançamos 411 seguidores.

Por fim, é relevante destacar a mobilização observada no sentido de impulso de uma economia criativa articulada com políticas públicas a partir de projetos culturais elaborados por artesãos e associações de mamulengueiros. Este ano foram aprovados em editais de incentivo à cultura do Estado Pernambuco os projetos Elaboração do plano museológico do Museu do Mamulengo de Glória de Goitá, de Givanildo Ferreira, e Mulheres Mamulengueiras: uma nova geração, da Mestra Titinha.

Acreditamos, assim, termos alcançado uma renovação do processo comunicacional para uma manifestação tradicional, mantendo intacta a sua memória e valores. Com o impacto causado, esperamos que o poder público fique mais atento para a riqueza cultural dessa expressão e a própria comunidade do Teatro de Mamulengo ganhe visibilidade e, em um passo futuro, vislumbre novos modelos econômicos que o integre ainda mais no âmbito das indústrias criativas.

\section{REFERÊNCIAS}

ABNT. Associação Brasileira de Normas Técnicas. 2021. Disponivel em: https://www.normasabnt.org/. Acesso em: 08 nov. 2019.

BARBERO, Jesús Martin. Diversidade em convergência. Disponível em: http://dx.doi.org/10.11606/ issn.1982-8160.v8i2p15-33. Acesso em: 04 nov. 2019. 


\section{Brazilian Creative Industries}

BENDASSOLLI, Pedro F. et al. Indústrias criativas: definição, limites e possibilidades. Revista de Administração de Empresas [online], v. 49, n. 1, p. 10-18, 2009. Disponivel em: https://doi.org/10.1590/S003475902009000100003. Acesso em: 29 set. 2021.

BORBA FILHO, Hermilo. Fisionomia e Espírito do mamulengo. São Paulo: Companhia Editora Nacional, Vol. 332, 1966. Disponivel em: https://bdor.sibi.ufrj.br/handle/doc/380. Acesso em: 29 set. 2021.

BORBA FILHO, Hermilo. Espetáculo Popular do Nordeste. São Paulo: Buriti, 1966.

BROCHADO, Izabela Costa. Teatro de Bonecos Popular do Nordeste Mamulengo, Babau, João Redondo e Cassimiro Coco: Patrimônio Cultural do Brasil. Arte Da Cena (Art on Stage), 1. ed, vol. 2, 2015. p. 67-87.

BROWN, Tim. Design Thinking: uma metodologia poderosa para decretar o fim das velhas ideias. Rio de Janeiro: Alta Books, 2017.

CASTELLS, Manuel. A sociedade em Rede. São Paulo: Paz \& Terra, 2017.

Instituto do Patrimônio Histórico e Artístico Nacional (IPHAN). Dossiê Interativo. Registro do Teatro de bonecos popular do Nordeste: Mamulengo, Cassimiro do coco, Babau, João Redondo como patrimônio cultural do Brasil. Ministério da Cultura, Processo Nº1450.004801/2004-30, Brasília, 2004.

Federação das Indústrias do Rio de Janeiro (FIRJAN). Mapeamento da indústria criativa no Brasil. 2012.

GIBSON, Willian. Neuromancer. São Paulo: Editora Aleph, 1984.

HALL, Stuart. A identidade cultural na pós-modernidade. 11. ed. Tradução: Tomaz T. Silva e Guacira L Louro. Rio de Janeiro: DP\&A, 1992.

HOWKINS, John. Economia Criativa: como ganhar dinheiro com ideias criativas. São Paulo: MBook, 2013. ISBN: 9788576802068.

JAMBEIRO, Othon, Fabio Ferreira. Compreendendo as Indústrias Criativas de Mídia: contribuição da economia política da comunicação. Revista Comunicação Midiática, n. 3, vol. 7, 2012, p. 178-194. Disponível em: https://www2.faac.unesp.br/comunicacaomidiatica/index.php/CM/article/view/272. Acesso em: 29 set. 2021.

JASIELLO, Franco Maria. Mamulengo - o teatro mais antigo do mundo. Natal: A.S. Editores, 2003.

LÉVY, Pierre. Cibercultura. São Paulo: Editora 34, 2010. 


\section{Brazilian Creative Industries}

Ministério da Cultura. Plano da Secretaria da Economia Criativa: Políticas, diretrizes e ações (2011 a 2014). Brasilia, 2011. ISBN - 978-85-60618-03-3.

OLIVEIRA, Djalma P. Planejamento estratégico: conceitos, metodologia e práticas. São Paulo: Atlas, 2013.

SANTOS. Fernando. A. G. Mamulengo, um povo em forma de bonecos. Recife: CEPE, 1979.

SHIRKY, Clay. Lá vem todo mundo: O poder de organizar sem organização. Rio de Janeiro, Zahar, 2012. 